\title{
Clinicopathologic characteristics and prognosis of proximal and distal gastric cancer
}

This article was published in the following Dove Press journal:

OncoTargets and Therapy

\author{
Xuefeng $\mathrm{Yu}^{1}, *$ \\ Fulan $\mathrm{Hu}^{2}, *$ \\ Chunfeng $\mathrm{Li}^{\prime}$ \\ Qiang Yao' \\ Hongfeng Zhang' \\ Yingwei Xue' \\ 'Department of Gastrointestinal \\ Surgery, Harbin Medical University \\ Cancer Hospital, Harbin Medical \\ University, Harbin, China; \\ ${ }^{2}$ Department of Epidemiology, Public \\ Health College, Harbin Medical \\ University, Harbin, China \\ *These authors contributed equally \\ to this work
}

\begin{abstract}
Background and objectives: The dismal prognosis of gastric cancer patients is a global problem. We aim to evaluate the clinicopathologic features and prognostic factors of proximal and distal gastric cancer.

Materials and methods: Gastric cancer cases diagnosed and treated at the same surgical unit between 2007 and 2010 were reviewed. Follow-up data from all patients were collected for at least 5 years until 2015. A total of 964 patients were studied (distal gastric cancer [DG], n=777 and proximal gastric cancer [PG], $\mathrm{n}=187$ ).

Results: DG patients had a relatively higher percentage of females, more thorough therapy (R0 [D0/D1/D2]), fewer combined organ resections, younger age, smaller tumors $(<5 \mathrm{~cm})$, shorter surgery durations, less blood loss during surgery, and a relatively lower percentage of nodal metastases and a TNM stage of $4(p<0.05)$. A significantly higher 5-year survival rate was observed in DG patients compared to PG patients (DG: $51 \%$, PG: $28 \% ; p<0.001$ ). A multivariate analysis demonstrated that tumor size, blood loss during surgery, surgery approach of lymph node dissection, treatment with palliative surgery, histopathologic type, TNM stage, and tumor location were independent predictors of poor outcome.

Conclusion: The different characteristics and prognosis of DG and PG cases have implications for the development of guiding strategies for a surgical program and assessment of prognosis of gastric cancer patients based on tumor location.
\end{abstract}

Keywords: gastric cancer, tumor location, clinicopathologic features, prognosis, distal gastric cancer, proximal gastric cancer

\section{Introduction}

The prognosis of gastric cancer patients worldwide has been dismal over the past several decades. ${ }^{1,2}$ Gastric cancer is the most common cause of cancer-related deaths, as reported by the World Health Organization. ${ }^{3}$ Until recently, a steady decrease in the incidence and mortality rate of gastric cancer has been observed in most parts of the world. ${ }^{4}$ Several factors partly explain this favorable trend, such as decreased smoking, earlier detection, management of Helicobacter pylori and Epstein-Barr virus infections, and dietary improvements including increased availability of fresh fruits and vegetables and a decreased reliance on salted and preserved foods. ${ }^{5-7}$ However, the absolute number of gastric cancer cases and deaths is still a substantial burden on the world's economy, especially as the world population and the life expectancy are increasing. It has been reported that a total of 989,600 new gastric cancer cases and 738,000 gastric cancer-related deaths were estimated in 2008 , accounting for $8 \%$ of total cancer cases and $10 \%$ of total cancer-related deaths. Over $70 \%$ of new gastric cancer cases and deaths occur in developing countries, and 5-year relative survival rates of around $20 \%$ or less are frequently reported..$^{8,9}$
Department of Gastrointestinal Surgery, Harbin Medical University Cancer Hospital, 150 Haping Road, Nangang District, Harbin I50040, Heilongjiang Province, China Email xyw80I@I63.com 
In recent years, the incidence of proximal gastric cancer has increased, while the incidence of distal gastric cancers has fallen in Western countries, with the reverse trend occurring in Asian countries. ${ }^{1,2,8,10}$ In addition, Asian patients show greater overall survival despite having similar clinicopathologic characteristics and treatments to those of patients in Western countries. ${ }^{11}$ A study in Portugal indicated that proximal and distal gastric cancers are significantly different in terms of patient survival, tumor size, venous invasion, nodal status, and overall stage. ${ }^{12}$ Gastric cancer rates are about twice as high in males as in females. ${ }^{8}$ Age and family history are also correlated with gastric cancer incidence. These factors, together with different clinical and pathologic characteristics, can lead to different prognoses for patients. Thus far, several studies investigating gastric tumor location and correlation with prognosis have contradicted each other, where some have shown a better prognosis in patients with a tumor in the lower third of the stomach compared to the upper regions, ${ }^{12,13}$ while other studies have shown no relationship between prognosis and gastric tumor location. ${ }^{14}$

Therefore, the relationship between proximal and distal locations of gastric cancer, as well as other characteristics of gastric cancer and survival in patients remains to be validated. In this study, we investigated the relationship between epidemiological and clinicopathologic characteristics of gastric cancer patients, surgical approaches utilized for these patients, and information on the specific tumor locations and prognosis in a large cohort of patients.

\section{Materials and methods}

\section{Patients and data}

Patients who previously underwent gastric excision surgery between 2007 and 2010 at the Cancer Hospital of Harbin Medical University to treat gastric cancer were recruited for this study. Written informed consent was obtained from all patients for the use of their medical data for research. The study protocol was verified to be in accordance with the guidelines of the Helsinki Declaration, and was approved by the Ethics Committee of the Harbin Medical University Cancer Hospital (KY2015-01). Data for all patients who had received laparoscopic surgery and who had complete follow-up data for at least 5 years were collected (until 2015). Patients who had received neoadjuvant chemotherapy were excluded. Patients with other cancers pre- or postoperatively were also excluded. A total of 964 patients with tumors located in the upper (proximal) or lower (distal) third of the stomach were enrolled according to the Japanese
Gastric Cancer Association specifications (Classification of Gastric Carcinoma, 14th edition, 2010; Figure 1). Proximal and distal gastric cancer patients were assigned to proximal gastric cancer (PG) and distal gastric cancer (DG) groups, respectively.

The following epidemiological, clinical, and pathologic parameters were collected for each patient: age, gender, family history of cancer, height, weight, body mass index (BMI; thin: <18.5; standard: 18.5-24.0; and overweight: $\geq 24$, as defined by the Working Group on Obesity in China), tumor size, surgery duration, blood loss at surgery, multifocality (two or more tumors), histopathologic type (well differentiation: high and middle differentiation; poor differentiation: low differentiation; and mixed differentiation: signet ring cell carcinoma, mucinous adenocarcinoma, and non-tubular adenocarcinoma), surgical approaches of lymph node dissection (R0 [D0/D1/D2], reduction surgery [R1/R2], and palliative surgery [laparotomy/bypass]; D0: the tumor is resected without a lymph node dissection; D1: the tumor is resected with a lymph node dissection at the first site near the stomach; D2: in addition to the criteria of D1, a wider range of lymph node dissections are carried out, and surgery is more thorough, but the trauma and surgery duration is relatively large; R0: the tumor is completely removed, and residual tumor cells cannot be observed under the microscope or by the naked eye; R1: the tumor is not completely removed, and residual tumor cells can be observed under the microscope; R2: residual tumor cells can be observed by the naked eye),

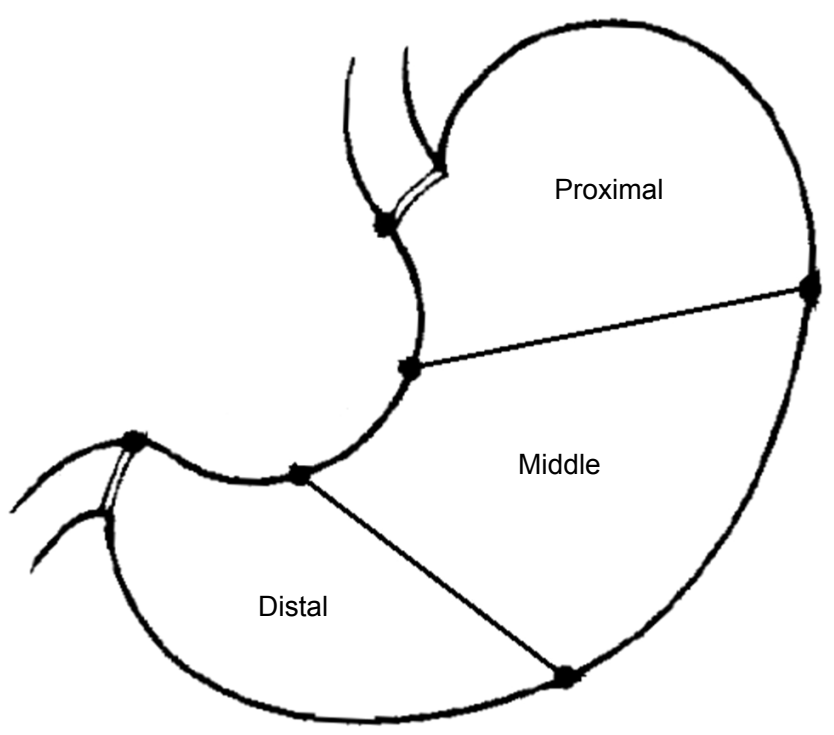

Figure I The location of gastric cancers. The stomach is divided into three parts including the upper third (proximal), middle third, and lower third (distal), according to JGCA Classification of Gastric Carcinoma.

Abbreviation: JGCA, Japanese Gastric Cancer Association. 
combined resection (such as liver, spleen, diaphragm, transverse resection), Borrmann type (Borrmann type 0, I, II, III, and IV), TNM stage, total number of resected lymph nodes, and node metastases.

\section{Statistical analysis}

All statistical analyses were performed with SAS 9.1 (SAS Institute, Cary, NC, USA) software. For analyzing basic characteristics, a Student's $t$-test was used for continuous variables and a chi-squared test was used for categorical variables. The endpoint was overall survival, which was calculated based on the time of the first diagnosis of gastric cancer to death from any cause or until October 2015. The survival curves were estimated using the Kaplan-Meier product-limit method. The cumulative survival probability was calculated for the fifth year. Proportional hazards regression models were fitted with computing hazard ratios and the corresponding 95\% CI. All statistical tests were two sided, with $p$-values $<0.05$ being considered statistically significant.

\section{Results}

\section{Characteristics of subjects}

In this study, 964 patients were included. According to clinical records, 777 patients $(80.6 \%)$ had DG tumors and 187 (19.4\%) patients had PG tumors, with an incidence ratio of 4.16:1. Therefore, a higher tumor incidence was found in the lower gastric region.

As shown in Table 1, no significant differences were observed in the distribution of patients' BMIs, multifocality, histopathologic type, and nodal metastases between the two tumor locations.

There were significant differences in distribution of gender, age, family history of cancer, tumor size, surgery duration, blood loss during surgery, approaches of lymph node dissection, combined resection, Borrmann type, total number of resected lymph nodes, nodal metastases, and TNM stage between the DG and PG groups $(p<0.05)$. A relatively higher percentage of female patients, younger age, smaller tumor size $(<5 \mathrm{~cm})$, shorter surgery duration, lesser blood loss during surgery, and a relatively lower percentage of nodal metastases and a TNM stage of 4 were characteristic of DG patients. In addition, the metastasis rate of the total number of resected lymph nodes was significantly lower in the DG group (25.1\%) compared with the PG group (44.1\%; $p<0.01$ ). Almost $20 \%$ of DG patients reported a family history of cancer, and only $12 \%$ of PG patients reported a family history of cancer. More patients underwent lymph node dissection R0, and fewer patients were subjected to the combined organ resection and had TNM stage 4 among DG patients compared to $\mathrm{PG}$ patients.

\section{Comparison and correlation of survival and clinicopathologic characteristics in DG and PG patients}

Cumulative survival curves for gastric cancer patients based on tumor location are illustrated in Figure 2. Five-year survival rates were $51 \%$ for DG patients and $28 \%$ for $P G$ patients. A significant difference was observed in the survival of DG and PG patients $(p<0.001)$.

As shown in Table 2, a univariate analysis of survival revealed significantly different survival curves based on the following parameters: increased tumor size, approaches of lymph node dissection, histopathologic type, nodal metastases, and TNM stage for patients in the PG and DG groups. However, for patients in the DG group, additional parameters including age, BMI, surgery duration, blood loss during surgery, multifocality, combined resection, and Borrmann type were correlated with a 5-year survival. Further comparison of survival between the two groups showed that patients with increased tumor size and nodal metastases had worse survival if tumors were in the proximal stomach, compared to patients with tumors in the distal stomach. Patients who underwent lymph node dissection (R0/D0/D1/D2) and reduction surgery, and who had tumors with higher differentiation, had better survival outcomes, only if the tumors were located in the distal region of the stomach. In addition, patient survival was better if the cancers were located in the distal region of the stomach compared to patients with tumors in the proximal region, except for patients who underwent palliative surgery, had Borrmann type III and IV tumors, or TNM stage 1 and 4 tumors. For example, patients with a family history of cancer and a higher body weight had better survival in the DG group.

Multivariate analysis (Table 3) revealed that when appropriate significant factors were taken into consideration, tumor size, blood loss during surgery, radical degree, performance of palliative surgery, histopathologic type, TNM, and the location of the cancer were independent predictors of poor outcome.

\section{Discussion}

In this study, epidemiological and clinicopathologic characteristics were analyzed for patients with DG and PG, and the prognostic factors for patients with different locations of gastric cancer were determined. 
Table I Clinicopathologic characteristics of gastric cancer patients: comparison between lower and upper gastric carcinomas patients

\begin{tabular}{|c|c|c|c|}
\hline & DG, n (\%) & PG, n (\%) & $p$-value \\
\hline Gender & & & 0.030 \\
\hline Male & $566(72.8)$ & I56 (83.4) & \\
\hline Female & $211(27.2)$ & $31(16.6)$ & \\
\hline Age (years) & & & 0.046 \\
\hline$<40$ & $52(6.7)$ & $5(2.7)$ & \\
\hline $40-65$ & $499(64.2)$ & $116(62.0)$ & \\
\hline$\geq 65$ & $226(29.1)$ & $66(35.3)$ & \\
\hline BMI $\left(\mathrm{kg} / \mathrm{m}^{2}\right)$ & & & 0.120 \\
\hline$<18.5$ & $97(12.5)$ & $29(15.5)$ & \\
\hline $18.5-24$ & $463(59.6)$ & $96(51.3)$ & \\
\hline$\geq 24$ & $217(27.9)$ & $62(33.2)$ & \\
\hline Family history of cancer & & & 0.014 \\
\hline No & $623(80.2)$ & $165(88.0)$ & \\
\hline Yes & $154(19.8)$ & $22(12.0)$ & \\
\hline Tumor size $(\mathrm{cm})$ & & & $<0.001$ \\
\hline$<5$ & $367(47.3)$ & $46(24.6)$ & \\
\hline$\geq 5$ & $410(52.7)$ & |4| (75.4) & \\
\hline Surgery duration (min) & & & $<0.001$ \\
\hline$\leq 150$ & $44 \mathrm{I}(56.8)$ & $62(32.2)$ & \\
\hline$>150$ & $336(43.2)$ & $125(67.8)$ & \\
\hline Blood loss during surgery $(\mathrm{mL})$ & & & $<0.001$ \\
\hline$\leq 200$ & $664(85.5)$ & $135(72.2)$ & \\
\hline$>200$ & $113(14.5)$ & $52(27.8)$ & \\
\hline Multifocality & & & 0.734 \\
\hline Single & $757(97.4)$ & $183(97.9)$ & \\
\hline Multiple $(\geq 2)$ & $20(2.6)$ & $4(2.1)$ & \\
\hline Approach of lymph node dissection & & & 0.010 \\
\hline R0 (D0/DI/D2) & $598(77.0)$ & $124(66.3)$ & \\
\hline Reduction surgery (RI/R2) & $130(16.7)$ & $47(25.1)$ & \\
\hline Palliative surgery (laparotomy/bypass) & $49(6.3)$ & $16(8.6)$ & \\
\hline Combined resection & & & $<0.001$ \\
\hline No & $763(98.2)$ & $164(87.7)$ & \\
\hline Yes & $14(1.8)$ & $23(12.3)$ & \\
\hline Borrmann type ( $n=904)$ & & & $<0.001$ \\
\hline Borrmann 0 & $50(6.8)$ & I (0.6) & \\
\hline Borrmann I & $84(11.5)$ & $34(19.8)$ & \\
\hline Borrmann II & $112(15.3)$ & $17(9.9)$ & \\
\hline Borrmann III & $46 I(63.0)$ & $109(63.4)$ & \\
\hline Borrmann IV & $25(3.4)$ & II (6.4) & \\
\hline Histopathologic type (n=924) & & & 0.569 \\
\hline Well differentiation & $193(25.9)$ & $46(25.8)$ & \\
\hline Poor differentiation & $324(43.5)$ & $84(47.2)$ & \\
\hline Mixed differentiation & $229(30.7)$ & $48(27.0)$ & \\
\hline Total number of resected lymph nodes, & $12,198(15.7 \pm 3.6)$ & $2,319(12.4 \pm 4.2)$ & $<0.001$ \\
\hline \multicolumn{4}{|l|}{$\mathrm{n}($ mean $\pm \mathrm{SD})$ and metastases } \\
\hline No & $9,140(74.9)$ & I,297 (55.9) & $<0.001$ \\
\hline Yes & $3,058(25.1)$ & $\mathrm{I}, 022(44.1)$ & \\
\hline Nodal metastases & & & $<0.001$ \\
\hline No & $746(95.0)$ & $169(90.4)$ & \\
\hline Yes & $31(4.0)$ & $18(9.6)$ & \\
\hline $\mathrm{TNM}^{\mathrm{a}}$ & & & $<0.001$ \\
\hline I & 177 (22.8) & $10(5.4)$ & \\
\hline 2 & $225(28.9)$ & $62(33.2)$ & \\
\hline 3 & $343(44.2)$ & 97 (5।.9) & \\
\hline 4 & $32(4.1)$ & $18(9.6)$ & \\
\hline
\end{tabular}

Note: a TNM stage is based on the AJCC Cancer Staging Manual, seventh edition (2010).

Abbreviations: AJCC, American Joint Committee on Cancer; BMI, body mass index; DG, distal gastric cancer; PG, proximal gastric cancer. 


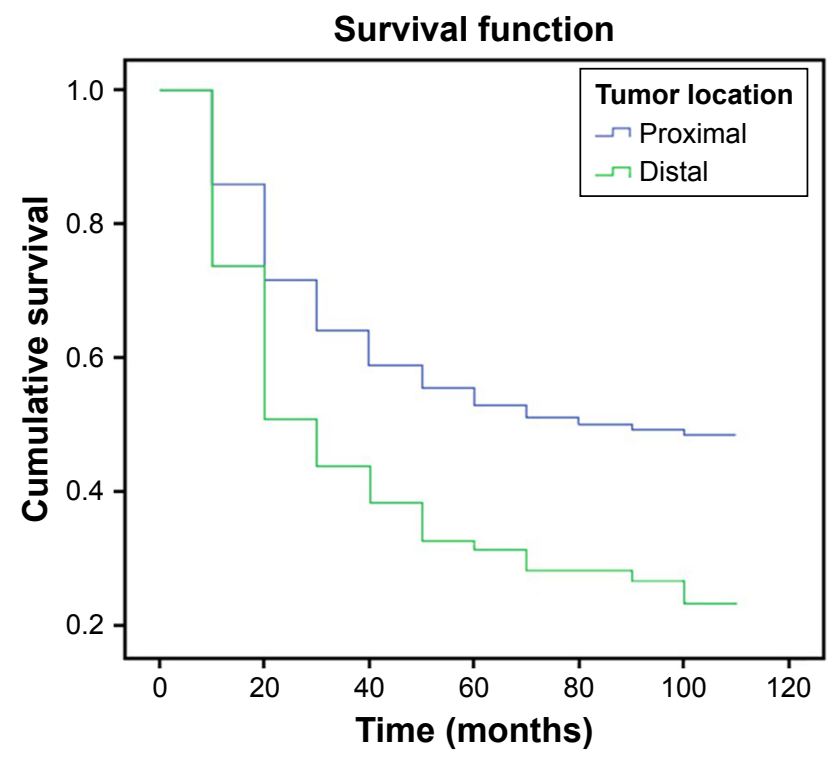

Figure 2 Five-year survival following curative gastrectomy according to tumor location. Cumulative survival was better for patients with distal gastric cancer than proximal gastric cancer patients $(p<0.001)$.

Gender is an important factor affecting the occurrence of gastric cancer, where stomach cancer rates worldwide are about twice as high in males compared to females. In 2014, the gender ratios of newly diagnosed gastric cancer cases were 1.6:1 (male:female) in the USA and 2.2:1 in China. ${ }^{9,15-17}$ In this study, the total ratio of males to females was $2.8: 1$, with a high ratio $(5.0: 1)$ found for patients with PG. One of the reasons for this observation may be because of poor diet and unhealthy habits in men, such as smoking or alcohol consumption. ${ }^{18}$

There was a relatively higher frequency of young patients in the DG group compared to the PG group, with the average age being significantly lower in the DG group than in the PG group. Survival decreased in DG patients with increasing age of diagnosis. In addition, there was a higher rate of family history of cancer (19.8\%) in DG patients, which suggests a genetic predisposition in patients in the DG group. The differences in epidemiology may be from these genetic differences. For PG patients, the presence of aneuploidy and a high S-phase fraction might affect the biological behavior of gastric cancer. ${ }^{19}$

In terms of survival, the patients with multifocal tumors in the DG group had a better prognosis than the patients with a single tumor ( $80 \%$ vs 50\%). In the DG group, multifocality can cause patients to experience significant symptoms and, therefore, result in early doctor visitation and treatment, while symptoms of patients in the PG group are relatively indistinct and treatment is usually late, which may partly explain the differences in survival of patients with multifocal tumors.
In addition, the degree of surgical complexity of DG tumors was significantly lower than that of PG tumors. In this study, both the average surgery duration and the amount of blood lost from surgery were less in DG patients than in PG patients. However, the shorter surgical time does not equate to a decrease in lymph node dissections. The percentage of patients who underwent surgery with lymph node dissection R0 was $77 \%$ for the DG group and $66.3 \%$ for the PG group. The longer surgical time for the PG group was mainly because of the more advanced TNM stage of the tumors, which required a more complicated radical surgery compared with that for DG cases. In the DG group, there was a significantly worse survival outcome with increasing surgical duration. However, shorter surgery time is not always superior. There were more early-stage gastric cancers found in DG patients; therefore, D0 or D1 lymphadenectomies were often used and a Billroth I anastomosis was more readily performed. Thus, surgery time was minimized. However, for PG patients, this trend was not observed for the few early-stage cases. Whether a splenectomy should be performed together with a gastrectomy was once a highly debated topic. Currently, many researchers agree that a prophylactic splenectomy should not be utilized for upper gastric surgery. ${ }^{20-22}$ In this study, $12.3 \%$ of patients in the PG group had a combined organ resection, while only $1.8 \%$ of patients in the DG group had this type of resection. The adjacent organs resected in patients included the spleen, the tail of the pancreatic corpus, the left adrenal gland, peritoneum, and diaphragm. Normally, PG cancers are large, are of an advanced stage, and do not involve adjacent vital organs. Therefore, adjacent organs have a higher resection rate. In the DG group, most of the tumor invasions were found in the head of the pancreatic corpus, duodenal and transverse colon. Patients with combined resection have more complications with no additional survival benefit. ${ }^{23,24}$ Therefore, the number of patients who underwent a combined resection was fewer in the DG group than in the PG group.

In this study, DG patients had smaller tumors at an earlier stage, which could be attributed to an early diagnosis. The gastric antral area is the retention area of gastric juice, and even a small lesion can lead to the regurgitation of acid and burning symptoms from gastric acid. However, patients with gastric cardiac lesions will visit a doctor only when dysphagia caused by larger tumors is felt, and therefore, diagnosis occurs late. Borrmann type III was the main type of gastric cancer in both DG and PG groups, and the DG and PG groups had significantly different Borrmann types in this study, which is similar to a previously published report. ${ }^{25}$ A report from Iran indicated that tumors from upper 
Table 2 Univariate analysis of survival according to tumor location in gastric cancer patients

\begin{tabular}{|c|c|c|c|c|c|c|c|c|}
\hline & \multicolumn{3}{|l|}{ DG } & \multicolumn{3}{|l|}{ PG } & \multicolumn{2}{|l|}{ DG vs PG } \\
\hline & $\begin{array}{l}\text { 5-year } \\
\text { survival }\end{array}$ & HR (95\% Cl) & $p$-value & $\begin{array}{l}\text { 5-year } \\
\text { survival }\end{array}$ & HR (95\% Cl) & $p$-value & HR (95\% Cl) & $p$-value \\
\hline Total & $51 \%$ & & & $28 \%$ & & & & $<0.001$ \\
\hline \multicolumn{9}{|l|}{ Gender } \\
\hline Male & $50 \%$ & I & & $27 \%$ & 1 & & I.87 (I.50, 2.32) & 0.001 \\
\hline Female & $55 \%$ & $0.86(0.68,1.09)$ & 0.204 & $35 \%$ & $0.85(0.53,1.36)$ & 0.492 & $1.81(1.12,2.94)$ & 0.018 \\
\hline \multicolumn{9}{|l|}{ Age (years) } \\
\hline$<40$ & $63 \%$ & I & & $20 \%$ & I & & $3.87(1.30,11.5 \mathrm{I})$ & 0.019 \\
\hline $40-65$ & $53 \%$ & I.50 $(0.93,2.42)$ & 0.102 & $31 \%$ & $0.65(0.24,1.78)$ & 0.401 & $1.80(1.40,2.33)$ & 0.000 \\
\hline$\geq 65$ & $45 \%$ & I.8I (I.II, 2.98) & 0.017 & $25 \%$ & $0.76(0.27,2.11)$ & 0.587 & $1.77(1.27,2.47)$ & 0.004 \\
\hline \multicolumn{9}{|l|}{ BMI $\left(\mathrm{kg} / \mathrm{m}^{2}\right)$} \\
\hline$<18.5$ & $38 \%$ & I & & $38 \%$ & 1 & & I.54 $(0.79,2.98)$ & 0.201 \\
\hline $18.5-24$ & $46 \%$ & $0.82(0.56,1.20)$ & 0.302 & $31 \%$ & $0.85(0.44,1.66)$ & 0.638 & $1.62(1.12,2.36)$ & 0.012 \\
\hline$\geq 24$ & $59 \%$ & $0.59(0.38,0.92)$ & 0.023 & $25 \%$ & $0.91(0.45,1.83)$ & 0.791 & $2.47(1.52,4.02)$ & $<0.001$ \\
\hline \multicolumn{9}{|l|}{ Family history of cancer } \\
\hline No & $50 \%$ & I & & $29 \%$ & 1 & & $\mathrm{I} .80(\mathrm{I} .45,2.23)$ & 0.001 \\
\hline Yes & $56 \%$ & $0.80(0.6 \mathrm{I}, 1.05)$ & 0.113 & $27 \%$ & $0.98(0.58,1.66)$ & 0.938 & $2.20(I .27,3.81)$ & 0.011 \\
\hline \multicolumn{9}{|l|}{ Tumor size $(\mathrm{cm})$} \\
\hline$<5$ & $73 \%$ & 1 & & $44 \%$ & 1 & & $2.58(1.67,3.97)$ & $<0.00$ I \\
\hline$\geq 5$ & $32 \%$ & $3.70(2.94,4.67)$ & 0.001 & $23 \%$ & $1.92(1.25,2.96)$ & 0.004 & $1.28(1.03,1.61)$ & 0.029 \\
\hline \multicolumn{9}{|l|}{ Surgery duration $(\mathrm{min})$} \\
\hline$\leq 150$ & $55 \%$ & I & & $33 \%$ & I & & $1.82(1.28,2.59)$ & 0.002 \\
\hline$>150$ & $47 \%$ & $1.29(1.05,1.58)$ & 0.021 & $27 \%$ & $1.20(0.82,1.76)$ & 0.363 & $1.73(1.34,2.24)$ & 0.001 \\
\hline \multicolumn{9}{|c|}{ Blood loss during surgery $(\mathrm{mL})$} \\
\hline$\leq 200$ & $55 \%$ & 1 & & $32 \%$ & 1 & & $1.86(1.46,2.36)$ & $<0.001$ \\
\hline$>200$ & $37 \%$ & $1.73(1.32,2.25)$ & 0.003 & $24 \%$ & $\mathrm{I} .37(0.93,2.01)$ & 0.107 & $1.44(0.97,2.15)$ & 0.068 \\
\hline \multicolumn{9}{|l|}{ Multifocality } \\
\hline Single & $50 \%$ & I & & $29 \%$ & 1 & & $\mathrm{I} .83(1.49,2.23)$ & 0.001 \\
\hline Multiple $(\geq 2)$ & $80 \%$ & $0.4 I(0.17,0.98)$ & 0.048 & $0 \%$ & $1.09(0.40,2.96)$ & 0.857 & $6.60(1.58,27.62)$ & 0.010 \\
\hline \multicolumn{9}{|c|}{ Approach of lymph node dissection } \\
\hline R0 (D0/DI/D2) & $64 \%$ & 1 & & $42 \%$ & 1 & & $1.95(1.49,2.55)$ & $<0.001$ \\
\hline Reduction surgery & $11 \%$ & $5.13(4.06,6.49)$ & 0.002 & $2 \%$ & $4.20(2.84,6.22)$ & 0.002 & $1.54(1.09,2.18)$ & 0.008 \\
\hline Palliative surgery & $0 \%$ & $13.82(9.92,19.24)$ & 0.001 & $0 \%$ & II. $50(6.35,20.84)$ & $<0.001$ & $1.14(0.64,2.04)$ & 0.652 \\
\hline \multicolumn{9}{|l|}{ Combined resection } \\
\hline No & $52 \%$ & 1 & & $29 \%$ & 1 & & $0.66(0.3 \mathrm{I}, \mathrm{I} .4 \mathrm{I})$ & 0.282 \\
\hline Yes & $21 \%$ & $3.15(1.73,5.75)$ & 0.004 & $22 \%$ & $1.21(0.74,1.96)$ & 0.454 & $1.86(1.51,2.30)$ & $<0.001$ \\
\hline \multicolumn{9}{|l|}{ Borrmann type } \\
\hline Borrmann 0 & $90 \%$ & I & & $100 \%$ & & & & \\
\hline Borrmann I & $62 \%$ & $4.65(1.80,11.98)$ & 0.003 & $30 \%$ & I & & $1.43(1.22,1.66)$ & 0.001 \\
\hline Borrmann II & $65 \%$ & $4.34(1.71,10.98)$ & 0.002 & $51 \%$ & $0.65(0.3 \mathrm{I}, \mathrm{I} .4 \mathrm{I})$ & 0.283 & $1.28(1.04,1.56)$ & 0.02 \\
\hline Borrmann III & $47 \%$ & $7.09(2.92,17.19)$ & 0.001 & $27 \%$ & $1.18(0.74,1.87)$ & 0.498 & $1.17(0.83,1.64)$ & 0.368 \\
\hline Borrmann IV & $35 \%$ & II.07 (4.08, 30.02) & $<0.001$ & $36 \%$ & $0.99(0.43,2.32)$ & 0.997 & $0.88(0.66,1.20)$ & 0.416 \\
\hline \multicolumn{9}{|l|}{ Histopathologic type } \\
\hline Well differentiation & $65 \%$ & 1 & & $41 \%$ & 1 & & $1.95(1.25,3.05)$ & 0.004 \\
\hline Poor differentiation & $46 \%$ & I.88 (I.42, 2.50) & $<0.001$ & $22 \%$ & $1.90(1.21,2.98)$ & 0.005 & $1.94(1.46,2.58)$ & $<0.001$ \\
\hline Mixed differentiation & $54 \%$ & $1.46(1.07,1.99)$ & 0.016 & $32 \%$ & I.49 $(0.90,2.50)$ & 0.123 & $1.95(1.31,2.91)$ & 0.001 \\
\hline \multicolumn{9}{|l|}{ Number of lymph nodes } \\
\hline$\leq 15$ & $56 \%$ & I & & $27 \%$ & I & & $2.17(2.67,2.82)$ & 0.001 \\
\hline$>15$ & $54 \%$ & $1.05(0.85,1.3 \mathrm{I})$ & 0.648 & $40 \%$ & $0.77(0.5 \mathrm{I}, 1.06)$ & 0.113 & $1.55(1.06,2.28)$ & 0.034 \\
\hline Nodal metastasis & & & & & & & & \\
\hline No & $81 \%$ & I & & $57 \%$ & I & & $2.85(1.74,4.67)$ & $<0.001$ \\
\hline Yes & $39 \%$ & $4.97(3.64,6.78)$ & $<0.001$ & $18 \%$ & $3.22(2.04,5.06)$ & $<0.001$ & $1.79(1.41,2.27)$ & $<0.001$ \\
\hline TNM & & & & & & & & \\
\hline I & $94 \%$ & I & I & $89 \%$ & 1 & I & $1.88(0.24, \mid 4.68)$ & 0.548 \\
\hline 2 & $65 \%$ & $7.08(3.66, \mid 3.68)$ & 0.003 & $50 \%$ & $6.22(0.85,45.69)$ & 0.078 & $1.61(1.06,2.46)$ & 0.034 \\
\hline 3 & $26 \%$ & $23.75(12.60,44.77)$ & $<0.001$ & $14 \%$ & $18.72(2.59,135.08)$ & 0.004 & $1.42(1.11,1.82)$ & 0.012 \\
\hline 4 & $0 \%$ & $97.98(47.64,201.5 \mathrm{I})$ & $<0.001$ & $0 \%$ & $57.63(7.60,436.77)$ & 0.001 & $1.03(0.58,1.84)$ & 0.923 \\
\hline
\end{tabular}

Abbreviations: BMI, body mass index; DG, distal gastric cancer; HR, hazard ratio; PG, proximal gastric cancer. 
Table 3 Multivariate analysis: independent predictors of outcome

\begin{tabular}{|c|c|c|}
\hline Variable & Hazard ratio & $p$-value \\
\hline \multicolumn{3}{|l|}{ Tumor size $(\mathrm{cm})$} \\
\hline$<5$ & 1 & \\
\hline$\geq 5$ & $1.59(1.26,2.00)$ & $<0.001$ \\
\hline \multicolumn{3}{|l|}{ Blood loss during surgery $(\mathrm{mL})$} \\
\hline$\leq 200$ & 1 & \\
\hline$>200$ & $1.46(1.16,1.84)$ & $<0.001$ \\
\hline \multicolumn{3}{|c|}{ Approach of lymph node dissection } \\
\hline R0 (D0/DI/D2) & 1 & \\
\hline Reduction surgery (RI/R2) & $3.20(2.58,3.98)$ & $<0.001$ \\
\hline Palliative surgery & $2.90(0.7 \mathrm{I}, \mathrm{II} .8 \mathrm{I})$ & 0.137 \\
\hline \multicolumn{3}{|l|}{ Histopathologic type } \\
\hline Well differentiation & 1 & \\
\hline Poor differentiation & $1.40(1.09,1.79)$ & 0.008 \\
\hline Mixed differentiation & $1.44(1.10,1.89)$ & 0.007 \\
\hline \multicolumn{3}{|l|}{ TNM } \\
\hline $\mathrm{I}+\mathrm{II}$ & 1 & \\
\hline III+IV & $3.78(3.02,4.74)$ & $<0.001$ \\
\hline \multicolumn{3}{|l|}{ Location } \\
\hline Distal & 1 & \\
\hline Proximal & $1.48(1.19,1.85)$ & $<0.001$ \\
\hline
\end{tabular}

gastric tissue show poor differentiation. ${ }^{10}$ In our study, tumor differentiation types were not significantly different between the DG and PG groups, but patients with well-differentiated tumors had a better prognosis, especially in the DG group. These differences may be partly attributed to the genetic differences between the Iranian and Chinese populations.

Patients with DG cancer had more resected lymph nodes compared to patients with PG cancer. In the DG group, a total of 12,198 lymph nodes including 3,058 metastases were resected. The total number of lymph nodes resected in the PG group was 2,319, including 1,022 metastases. The results suggest that lymph node metastases are more severe in PG cases, which may be one of the reasons that patients with lymph node metastases in the DG group had a better prognosis. Moreover, some reports indicate that patients with more resected lymph nodes have a better prognosis, ${ }^{26,27}$ which is similar in PG patients. In the PG group, with an increase in the number of lymph nodes resected, there was an improved survival $(27 \%$ vs $40 \%$ in stratification of number $\leq 15$ or $>15, p=0.113$ ). Therefore, it is necessary to resect more lymph nodes during surgery of PG patients.

A Cox regression analysis identified the approach of lymph node dissection, tumor size, and tumor stage as prognostic factors of gastric cancer, and these observations were in agreement with other reports. ${ }^{12,25,28}$ To the best of our knowledge, no other study has indicated tumor site as a predictor of survival for patients with gastric cancer. In this study, the DG group (51\%) showed a better 5-year survival than the PG group (28\%). In addition, studies have indicated that several Western countries have shown an increased incidence of PG cancers and a decreased incidence of DG cancers, and the trend is reversed in Asian countries. . $^{1,2,8,10}$ Therefore, the tumor site may be one of the reasons that Asian patients show superior overall survival.

\section{Conclusion}

In summary, differences in epidemiological and clinicopathologic characteristics, and the surgical approach of PG and DG cancers and the relationship with prognosis were analyzed. Patients with DG cancer were more likely to be diagnosed at a younger age, have a family history of cancer, and show multifocality and improved prognosis. Patients with PG cancer had the characteristics of late disease stage, large tumors, underwent more complex surgery, had a high rate of lymph node metastases, and worse prognosis. The reason that PG cancer is difficult to diagnose early may be because of the lack of symptoms and careful observation on the fundus of the stomach using endoscopy. Therefore, regular endoscopies and lowering the misdiagnosis rate should be important steps in improving the prognosis of $\mathrm{PG}$ cancer. These findings have implications for the development of guiding strategies for the surgical program and assessment of prognosis of gastric cancer arising at different locations. In addition, patients who had received neoadjuvant chemotherapy were excluded in this study. Further studies need to be done to ascertain the impact of neoadjuvant therapy in the outcomes of PG and DG cancers.

\section{Acknowledgment}

This work was supported by the Health and Family Planning Commission of Heilongjiang Province (no 2014-364).

\section{Disclosure}

The authors report no conflicts of interest in this work.

\section{References}

1. Msika S, Tazi MA, Benhamiche AM, Couillault C, Harb M, Faivre J, et al. Population-based study of diagnosis, treatment and prognosis of gastric cancer. Br J Surg. 1997;84(10):1474-1478.

2. Ajani JA, Mansfield PF, Ota DM. Potentially resectable gastric carcinoma: current approaches to staging and preoperative therapy. World $J$ Surg. 1995;19(2):216-220.

3. World Health Organization. Cancer: Fact Sheet. Updated November 2014. Available from: http://www.who.int/mediacentre/factsheets/fs297/ en/. Accessed January 6, 2016.

4. Bertuccio $\mathrm{P}$, Chatenoud L, Levi F, et al. Recent patterns in gastric cancer: a global overview. Int J Cancer. 2009;125(3):666-673.

5. Chen J, Bu XL, Wang QY, Hu PJ, Chen MH. Decreasing seroprevalence of Helicobacter pylori infection during 1993-2003 in Guangzhou, southern China. Helicobacter. 2007;12(2):164-169.

6. Kawakami E, Machado RS, Ogata SK, Langner M. Decrease in prevalence of Helicobacter pylori infection during a 10-year period in Brazilian children. Arq Gastroenterol. 2008;45(2):147-151. 
7. Tkachenko MA, Zhannat NZ, Erman LV, et al. Dramatic changes in the prevalence of Helicobacter pylori infection during childhood: a 10-year follow-up study in Russia. J Pediatr Gastroenterol Nutr. 2007; 45(4):428-432.

8. Jemal A, Bray F, Center MM, Ferlay J, Ward E, Forman D. Global cancer statistics. CA Cancer J Clin. 2011;61(2):69-90.

9. Roder DM. The epidemiology of gastric cancer. Gastric Cancer. 2002; 5(Suppl 1):5-11.

10. Norouzinia M, Asadzadeh H, Shalmani HM, Al Dulaimi D, Zali MR. Clinical and histological indicators of proximal and distal gastric cancer in eight provinces of Iran. Asian Pac J Cancer Prev. 2012;13(11): 5677-5679.

11. Chen Y, Haveman JW, Apostolou C, Chang DK, Merrett ND. Asian gastric cancer patients show superior survival: the experiences of a single Australian center. Gastric Cancer. 2015;18(2):256-261.

12. Pinto-De-Sousa J, David L, Seixas M, Pimenta A. Clinicopathologic profiles and prognosis of gastric carcinomas from the cardia, fundus/ body and antrum. Dig Surg. 2001;18(2):102-110.

13. Maehara Y, Moriguchi S, Kakeji Y, et al. Prognostic factors in adenocarcinoma in the upper one-third of the stomach. Surg Gynecol Obstet. 1991;173(3):223-226.

14. Siewert JR, Bottcher K, Stein HJ, Roder JD, Busch R. Problem of proximal third gastric carcinoma. World J Surg. 1995;19(4):523-531.

15. Yang L. Incidence and mortality of gastric cancer in China. World $J$ Gastroenterol. 2006;12(1):17-20.

16. Isobe $Y$, Nashimoto A, Akazawa K, et al. Gastric cancer treatment in Japan: 2008 annual report of the JGCA nationwide registry. Gastric Cancer. 2011;14(4):301-316.

17. Jeong O, Park YK. Clinicopathological features and surgical treatment of gastric cancer in South Korea: the results of 2009 nationwide survey on surgically treated gastric cancer patients. J Gastric Cancer. 2011; 11(2):69-77.

18. Kalish RJ, Clancy PE, Orringer MB, Appelman HD. Clinical, epidemiologic, and morphologic comparison between adenocarcinomas arising in Barrett's esophageal mucosa and in the gastric cardia. Gastroenterology. 1984;86(3):461-467.
19. Alberts SR, Cervantes A, van de Velde CJ. Gastric cancer: epidemiology, pathology and treatment. Ann Oncol. 2003;14(Suppl 2):ii31-ii36.

20. Nashimoto A, Yabusaki H, Matsuki A. The significance of splenectomy for advanced proximal gastric cancer. Int J Surg Oncol. 2012; 2012:301530.

21. Sasada S, Ninomiya M, Nishizaki M, et al. Frequency of lymph node metastasis to the splenic hilus and effect of splenectomy in proximal gastric cancer. Anticancer Res. 2009;29(8):3347-3351.

22. Yu W, Choi GS, Chung HY. Randomized clinical trial of splenectomy versus splenic preservation in patients with proximal gastric cancer. Br J Surg. 2006;93(5):559-563.

23. Yu HW, Jung DH, Son SY, et al. Risk factors of postoperative pancreatic fistula in curative gastric cancer surgery. J Gastric Cancer. 2013; 13(3):179-184.

24. Pacelli F, Cusumano G, Rosa F, et al. Multivisceral resection for locally advanced gastric cancer: an Italian multicenter observational study. JAMA Surg. 2013;148(4):353-360.

25. Park JC, Lee YC, Kim JH, et al. Clinicopathological features and prognostic factors of proximal gastric carcinoma in a population with high Helicobacter pylori prevalence: a single-center, large-volume study in Korea. Ann Surg Oncol. 2010;17(3):829-837.

26. Song W, Yuan Y, Wang L, et al. The prognostic value of lymph nodes dissection number on survival of patients with lymph node-negative gastric cancer. Gastroenterol Res Pract. 2014;2014:603194.

27. Biffi R, Botteri E, Cenciarelli S, et al. Impact on survival of the number of lymph nodes removed in patients with node-negative gastric cancer submitted to extended lymph node dissection. Eur J Surg Oncol. 2011; 37(4):305-311.

28. Pacelli F, Papa V, Caprino P, Sgadari A, Bossola M, Doglietto GB. Proximal compared with distal gastric cancer: multivariate analysis of prognostic factors. Am Surg. 2001;67(7):697-703.
OncoTargets and Therapy

\section{Publish your work in this journal}

OncoTargets and Therapy is an international, peer-reviewed, open access journal focusing on the pathological basis of all cancers, potential targets for therapy and treatment protocols employed to improve the management of cancer patients. The journal also focuses on the impact of management programs and new therapeutic agents and protocols on

\section{Dovepress}

patient perspectives such as quality of life, adherence and satisfaction The manuscript management system is completely online and includes a very quick and fair peer-review system, which is all easy to use. Visit http://www.dovepress.com/testimonials.php to read real quotes from published authors. 